\title{
AFLP analysis reveals high genetic diversity but low population structure in Coccidioides posadasii isolates from Mexico and Argentina
}

Esperanza Duarte-Escalante', Gerardo Zúñiga², María Guadalupe Frías-De-León ${ }^{3}$, Cristina Canteros ${ }^{4}$, Laura Rosio Castañón-Olivares ${ }^{1}$ and María del Rocío Reyes-Montes ${ }^{1 *}$

\begin{abstract}
Background: Coccidioides immitis and C. posadasii cause coccidioidomycosis, a disease that is endemic to North and South America, but for Central America, the incidence of coccidioidomycosis has not been clearly established. Several studies suggest genetic variability in these fungi; however, little definitive information has been discovered about the variability of Coccidioides fungi in Mexico (MX) and Argentina (AR). Thus, the goals for this work were to study 32 Coccidioides spp. isolates from MX and AR, identify the species of these Coccidioides spp. isolates, analyse their phenotypic variability, examine their genetic variability and investigate the Coccidioides reproductive system and its level of genetic differentiation.
\end{abstract}

Methods: Coccidioides spp. isolates from MX and AR were taxonomically identified by phylogenetic inference analysis using partial sequences of the Ag2/PRA gene and their phenotypic characteristics analysed. The genetic variability, reproductive system and level of differentiation were estimated using AFLP markers. The level of genetic variability was assessed measuring the percentage of polymorphic loci, number of effective allele, expected heterocygosity and Index of Association $\left(I_{A}\right)$. The degree of genetic differentiation was determined by AMOVA. Genetic similarities among isolates were estimated using Jaccard index. The UPGMA was used to contsruct the corresponding dendrogram. Finally, a network of haplotypes was built to evaluate the genealogical relationships among AFLP haplotypes.

Results: All isolates of Coccidioides spp. from MX and AR were identified as C. posadasii. No phenotypic variability was observed among the C. posadasii isolates from MX and AR. Analyses of genetic diversity and population structure were conducted using AFLP markers. Different estimators of genetic variability indicated that the $C$. posadasii isolates from MX and AR had high genetic variability. Furthermore, AMOVA, dendrogram and haplotype network showed a small genetic differentiation among the C. posadasii populations analysed from MX and AR. Additionally, the $I_{A}$ calculated for the isolates suggested that the species has a recombinant reproductive system.

Conclusions: No phenotypic variability was observed among the C. posadasii isolates from MX and AR. The high genetic variability observed in the isolates from $M X$ and $A R$ and the small genetic differentiation observed among the C. posadasii isolates analysed, suggest that this species could be distributed as a single genetic population in Latin America.

Keywords: Genotypic variability, Haplotypes, Reproductive system

\footnotetext{
*Correspondence: remoa@unam.mx

'Departamento de Microbiología y Parasitología, Facultad de Medicina,

Universidad Nacional Autónoma de México (UNAM), Ciudad Universitaria No. 3000, México, D. F. 04510, México

Full list of author information is available at the end of the article
} 


\section{Background}

Species of the genus Coccidioides, primarily Coccidioides immitis and C. posadasii, cause coccidioidomycosis, which is a disease endemic to North and South America [1]. This mycosis is most prevalent in the Southwestern United States (US), Northern Mexico (MX), Central America and the foothills region of South America [2]. The habitat conditions that permit the development of the saprophytic phase of these fungi are sandy soils in arid areas where the annual rainfall is less than $500 \mathrm{~mm}$ [3-5].

Coccidioidomycosis infection in humans and other mammals is caused by the inhalation of arthroconidia. The illness begins with acute respiratory symptoms that are typically benign and vanish spontaneously; however, the disease can evolve into progressive clinical forms that spread to the skin and subcutaneous, visceral and skeletal tissues. These severe progressive forms cause high morbimortality and are commonly associated with immunocompromised patients [6].

Coccidioidomycosis is an emerging disease because increased infection rates have been recorded in recent years from MX [7] and Argentina (AR) [8]. In endemic areas in the US, more than 100,000 primary human infections by Coccidioides spp. are estimated each year; a considerable increase in the incidence of this disease has been noted in recent years, particularly in California and Arizona. The increased incidence of the disease has been associated with a rise in the migration of individuals who have not previously been exposed to the fungus into the endemic areas [9].

The current epidemiology for coccidioidomycosis in MX is unknown, because no prevalence studies have been conducted in most Mexican states since 1960. However, according to the information that is available, more than 1,500 cases of primary coccidioidomycosis and 15 cases of disseminated disease are estimated annually. It is important to note that this estimate was based on epidemiological studies prior to 1994; since 1995, there are no records of coccidioidomycosis incidence in MX because this infection was excluded from reports prepared for the national epidemiological registry [10]. This suggests that the disease may have developed much as it has in the US, where prevalence and incidence rates have soared since the early 1990s [11].

Epidemiology in AR is similar to that in MX: there are few existing studies, although in recent years, several epidemiological studies have been performed. These studies include an investigation conducted by Canteros et al. [8] that sought to identify areas of endemic mycoses in 10 rural communities from the Teuco-Bermejito interfluve, which is in the Chaco province. Although results from this study demonstrated that Histoplasma capsulatum was the principal agent of endemic mycoses, the researchers also indicated that the climatic conditions of the area are optimal for Coccidioides development and thus that the potential for Coccidioides infections in the area should not be dismissed. In another recent study conducted by Canteros et al. [12], the authors performed a comprehensive retrospective review of all documented coccidioidomycosis cases in AR between 1892 and 2009. This review demonstrated that between 2006 and 2009, the disease incidence in the Catamarca province increased from a historical rate of less than 0.5 cases per 100,000 inhabitants to 2 cases per 100,000 inhabitants, indicating that coccidioidomycosis is an emerging disease in this region.

Because of the increased incidence of this disease in North and South America, several studies in recent decades have sought to apply molecular techniques to better understand the taxonomy and population biology of Coccidioides. Numerous studies, principally in the US, have focused on the genetic variability of $C$. immitis isolates and concluded that this fungus has high genetic recombination and no genetic structure among fungal isolates; however, the recombination process has never been observed [13-17]. A recent study that supports the presence of recombination was conducted by Jewell et al. [18], who used microsatellites to determine that outbreaks of coccidioidomycosis in Arizona, US, were caused by a single fungal clone that was likely hypervirulent, possessed a high level of genetic variation and showed no dominant subtypes among its isolates. The absence of genetic structure among C. immitis isolates and the presence of cryptic sex in both species of this fungus led to an investigation of whether isolates of $C$. posadasii, which is the dominant species in Latin American countries, have the same behavior as isolates of $C$. immitis, which is the dominant species in the Southwestern US. To find evidence that would indicate whether there is an expansion of the fungus in MX and AR, this study aimed to determine the phenoand genotypic variability and the population structure of two populations (MX and AR).

\section{Methods}

\section{Isolates}

Thirty two clinical isolates of Coccidioides spp. were used, 21 isolates from MX: one isolate (M0104) provided by Instituto Nacional de Neurología y Neurocirugía; 6 isolates (M1204, M1404, M1505, M2305, M2805 and M3005) provided by UMAE Hospital de Especialidades No. 71, Instituto Mexicano del Seguro Social; one isolate (M3905) provided by Instituto de Diagnóstico y Referencia Epidemiológicos, Secretaría de Salud; one isolate (M5406) provided by Clínica Derma Care; one isolate (M5708) provided by Hospital Central "Dr. Ignacio Morones Prieto"; 6 isolates (HU2, HU11, HU12, HU18, HU19 and HU24) and one reference strain (HU1) provided by Hospital Universitario, Universidad Autónoma de Nuevo León; 
three isolates (37.3, 5256 and $\mathrm{SiFe}$ ) provided by Departamento de Infectología, Instituto Nacional de Ciencias Médicas y Nutrición "Salvador Zubirán” and one isolate (MA) provided by Instituto Nacional de Pediatría; and 11 isolates from AR (972579, 073089, 073094, 073129, 073130, 073131, 083376, 083377, 083380, 083381 and 083382 ), provided by the Instituto Nacional de Enfermedades Infecciosas, ANLIS "Dr. Carlos G. Malbrán" (Additional file 1). The isolates and strains were preserved at $4^{\circ} \mathrm{C}$ in flasks with sterile water and in tubes with mycobiotic agar (Bioxón, Mexico, MX) both with and without mineral oil. The isolates and reference strain studied were deposited in the Coccidioides spp. Collection of the Laboratorio de Micología Molecular, Departamento de Microbiología y Parasitología, Facultad de Medicina, Universidad Nacional Autónoma de México (UNAM).

\section{Biosafety}

The culture and DNA extraction procedures for the isolates used in the present study were conducted in accordance with Biosafety Level 3 (BSL3) conditions.

\section{Monospore cultures}

From each isolate grown on mycobiotic agar for 1-2 weeks at $30^{\circ} \mathrm{C}$, a conidial suspension was prepared using 1 $\mathrm{mL}$ of phosphate buffer ( $\mathrm{pH} 7.4$ ) and $0.05 \%$ Tween 20 (PBST). This suspension was diluted (1:1000) and $50 \mu \mathrm{L}$ of the dilution was grown on mycobiotic agar. The Petri dishes were incubated at $30^{\circ} \mathrm{C}$ and observed for colony growth. One colony was selected from each plate and grown on mycobiotic agar slants at $30^{\circ} \mathrm{C}$. The monospore cultures were then preserved in sterile water at $4^{\circ} \mathrm{C}$.

\section{Identification of the species of the Coccidioides spp. isolates}

The DNA of each isolate was obtained following the procedure by Williams et al. [19] and Calderón et al. [20]. It was extracted and purified using the DNeasy Plant Mini kit (Qiagen GmbH, Hilden, GE). The mycelium was lysed using a FastPrep-24 instrument (MP Biomedicals, Solon, $\mathrm{OH}, \mathrm{US}$ ) by homogenisation through a pattern with four periods of $40 \mathrm{~s}$ each at a speed of $6 \mathrm{~m} / \mathrm{s}$ and placement of the tube on ice for $5 \mathrm{~min}$ between each period. The DNA concentration was determined by spectrophotometry and confirmed by gel electrophoresis on a $1.0 \%$ agarose gel with ethidium bromide $(10 \mu \mathrm{g} / \mathrm{ml})$, using different concentrations of $\lambda$ phage (Invitrogen, Carlsbad, CA, US). The DNA was stored at $4^{\circ} \mathrm{C}$.

The oligonucleotides designed by Bialek et al. [21] were used for PCR. For the first PCR reaction, the reaction mixture comprised $10 \mathrm{ng}$ of DNA in a $25 \mu \mathrm{L}$ reaction volume containing $1 \mathrm{X}$ buffer, $200 \mu \mathrm{M}$ dNTPs (Applied Biosystems, Inc., Foster City, CA, US), $2.5 \mathrm{mM} \mathrm{MgCl}_{2}, 1.0 \mathrm{U}$ of Taq polymerase (Applied Biosystems) and 100 pmol of each oligonucleotide, CoI (5' -GTACTATTAGGGAGGATAATC GTT-3') and CoII (5'-GGTCTGAATGATCTGACGCA$\left.3^{\prime}\right)$. The following program was used for the PCR: one cycle at $94^{\circ} \mathrm{C}$ for $5 \mathrm{~min}$, followed by 40 cycles of $94^{\circ} \mathrm{C}$ for $30 \mathrm{~s}$, $50^{\circ} \mathrm{C}$ for $30 \mathrm{~s}$ and $72^{\circ} \mathrm{C}$ for $1 \mathrm{~min}$ with a final extension step at $72^{\circ} \mathrm{C}$ for $5 \mathrm{~min}$. A second PCR reaction was then conducted. The reaction mixture for this second reaction comprised $2 \mu \mathrm{L}$ of the product from the first PCR in a total reaction volume of $25 \mu \mathrm{L}$ that was composed of buffer, 200 $\mu \mathrm{M}$ dNTPs (Applied Biosystems), $1.5 \mathrm{mM} \mathrm{MgCl} 2,1 \mathrm{U}$ of Taq polymerase (Applied Biosystems) and 100 pmol of each oligonucleotide, CoIII (5' -ATCCCACCTTGCGCTGTATG TTCGA-3') and CoIV (5'-GGAGACGGCTGGATTT TTTAACATG-3'). For the second PCR, the following program was used: one cycle at $94^{\circ} \mathrm{C}$ for $5 \mathrm{~min}$ followed by 40 cycles of $94^{\circ} \mathrm{C}$ for $30 \mathrm{~s}, 60^{\circ} \mathrm{C}$ for $30 \mathrm{~s}$ and $72^{\circ} \mathrm{C}$ for $1 \mathrm{~min}$ with a final extension step at $72^{\circ} \mathrm{C}$ for $5 \mathrm{~min}$. The amplifications were conducted in an Esco Swift ${ }^{\circ}$ Maxi $^{\text {тм }}$ thermocycler (ESCO, Hatboro, PA, US). The amplified products were then separated on $1.5 \%$ agarose gels in $0.5 \mathrm{X}$ TBE buffer at $100 \mathrm{~V}$ for $60 \mathrm{~min}$. A 100-bp DNA ladder (Invitrogen) was used to determine the molecular sizes of the products. The gel was visualised using a Gel Doc XR (Bio-Rad, CA, US) image documentation system.

To confirm the identity of all isolates as C. posadasii, the 526-bp amplicons obtained from the first PCR were purified using the QIAquick PCR kit (Qiagen) and sequenced at the Unidad de Biología Molecular, Instituto de Fisiología Celular, UNAM using an automated ABI Prism 3100 (Applied Biosystems) sequencer. The sequences were edited using Chromas Lite 2.3 software (http://www. technelysium.com.au/chromas.html) and the sequence alignments were analised by the BLAST algorithm [22] to check similarities among all fungal sequences deposited in the GenBank database.

\section{Phenotypic variation \\ Macromorphology}

The 32 C. posadasii isolates grown on mycobiotic agar at $30^{\circ} \mathrm{C}$ for 10 days were observed to identify the morphological characteristics of each culture (colony colour and texture).

\section{Growth rates}

To determine the growth rates of the isolates, each isolate was grown on Petri dishes containing YEGagar ( $1 \%$ yeast extract, $1 \%$ glucose and $1.5 \%$ agar) (Bioxón) for 10 days. Circles $7 \mathrm{~mm}$ in diameter were cut from the colony margins in each plate. Each circle was placed in the centre of a Petri dish with YEG-agar containing one of the following different $\mathrm{NaCl}$ concentrations: $0 \mathrm{M}(0 \%), 0.034 \mathrm{M}$ (2\%), 0.068 M (4\%), and $0.102 \mathrm{M}$ (6\%). The Petri dishes were 
then immediately incubated at $30^{\circ} \mathrm{C}$. Growth was determined by measuring the diameters of the colonies (cm) after 4, 8, 10 and 15 days of incubation. Each experiment was repeated four times. Subsequently, the growth rate for each isolate was determined using the following formula: growth rate $=[$ (diameter of the colony - diameter of inoculum)/15 days of incubation].

\section{Conidial size}

The diameters of 40 conidia from each isolate grown on mycobiotic agar (Bioxón) and incubated at $37^{\circ} \mathrm{C}$ for 10 days were measured using a calibrated ocular micrometre (Olympus America Inc., Melville, NY, US).

\section{Phenotypic data analysis}

The MATLAB ver. 6.1 software package (Mathworks, Inc., Natick, MA, US) was used to analyse the phenotypic data for the growth rates. A two-way factorial design with repeated measurements was used to evaluate the incubation times (in days) and the different $\mathrm{NaCl}$ concentrations in the growth media to determine whether the isolate growth rates differed. In addition, the isolates were analysed by comparing their various growth rates and classifying the samples by their countries of origin. To analyse the conidial size, means were compared using the Tukey test.

\section{Genotypic variability \\ Amplified Fragment Length Polymorphism (AFLP) assessments}

The AFLP analyses were performed with DNA from the monospore cultures in accordance with Vos et al. [23] and Duarte-Escalante et al. [24]. The DNA was restriction digested with the endonucleases EcoRI and MseI. After digestion, adaptors were ligated to the resulting fragments. The fragments were then preamplified using primers E (5'-GACTGCGTACCAATTC-3') and $M$ (5'-GACGATGAGTCCTGGTAA-3'). Following this preamplification, selective PCR was performed in which the selective primers were nearly identical to primer $\mathrm{E}$ or $\mathrm{M}$ but were extended by specific two- or threenucleotide combinations at their 3 ' terminus. Six primer combinations were used: $\mathrm{E}+\mathrm{AA}: \mathrm{M}+\mathrm{CAC}, \mathrm{E}+\mathrm{AA}: \mathrm{M}+\mathrm{CAT}$, $\mathrm{E}+\mathrm{AA}: \mathrm{M}+\mathrm{CTG}, \quad \mathrm{E}+\mathrm{AA}: \mathrm{M}+\mathrm{CTC}, \mathrm{E}+\mathrm{AC}: \mathrm{M}+\mathrm{CAT}$, and E+AC:M+CTC. Primer labeling was performed by phosphorylating the $5^{\prime}$ end of the Eco RI primers with $\left[\gamma-{ }^{32} \mathrm{P}\right]$ ATP and T4 polynucleotide kinase and the amplified materials were analysed on 5\% polyacrylamide slab gels. A 50-bp DNA ladder (Invitrogen) was used as a reference.

\section{Statistical analyses of AFLP results}

Bands on different gels between 100 and 400 bp were analysed. The AFLP markers were visually recorded, compared with the 50-bp DNA marker ladder, manually coded and translated into binary data that indicated either their presence (1) or absence (0) (Additional file 2). From this AFLP marker data, estimates of the genetic diversity of the MX and AR isolates were calculated using the Shannon Index (S), assuming that each genotypic marker represented a distinct locus [25], and Nei's measure of genetic diversity (h), calculated using allelic frequencies [26]. Additionally, an expected heterozygosity by population $(\mathrm{H})$ and an average heterozygosis (Hw) were calculated using allele frequencies in accordance with the Bayesian method employed by Zhivotovsky [27]. An AMOVA analysis using FMAD v1.1 $\beta$ software [28] was used to calculate the partitioning of the molecular variance of the C. posadasii isolates from MX and AR at one hierarchical level (geographic origin).

The statistical significance of Fst and the partitioned molecular variance were evaluated by performing 10,000 random data permutations [29]. The genetic similarity between isolates was calculated with the Jaccard index. The genetic relationships among isolates were assessed by mean of the Unweighted Pair Group Method with Arithmetic Mean (UPGMA) using the Jaccard matrix. Distortion of the inferred tree was assessed with the cophenetic correlation coefficient $(\mathrm{CCCr})$ which was calculated using the Mantel test [30]. Multivariate statistical methods were carried out using the NTSYS-PC program (version 2.0, Exeter software) [31]. In addition, a haplotype network was performed to evaluate the genealogical relationships among the AFLP haplotypes using the median-joining method [32] implemented in NETWORK 4.2.0.1 (http://www.fluxus-engineering.com/sharenet.htm) [33], where branches with different lengths represent levels of evolutionary change. The parameters used were $\varepsilon$ $=0,1: 1$ weight for transitions-transversions and connection criteria. To distinguish clonal and recombinant structures in C. posadasii, the Index of Association $\left(I_{A}\right)$, was used, which is a statistical test that measures the degree of non-random association between alleles at different loci (linkage disequilibrium) [34]. Therefore, $I_{A}$ is zero in strictly recombining populations and 1 in strictly clonal populations. $I_{A}$ was calculated using the LIAN 3.5 software [35].

\section{Results}

Identification of the species of the Coccidioides spp. isolates

All the sequences obtained (accession no. JQ919960JQ919967; JQ919969-JQ919977; JQ919979-JQ919994) were located between positions 902 and 1304 of Ag2/ PRA gene in the $C$. posadasii genome (accession no. AF013256). The 32 isolates of Coccidioides spp. from MX and AR were identified as C. posadasii with a nucleotide identity $>99 \%$, trough of the phylogenetic inference analysis (Additional file 3). 


\section{Phenotypic variation Macromorphology}

The isolates presented the macromorphology typically described for the C. posadasii. The texture of the colonies was generally fuzzy with smooth edges; several colonies had a powdery appearance. For the majority of the isolates, the colour of the front was white with buff components. The reverse side for most of the isolates was buff; however, isolates 073089, HU12 and 083378 exhibited a brown pigmentation (data not shown).

\section{Growth rates}

The $C$. posadasii isolates grown in YEG-agar medium containing 4 and $6 \% \mathrm{NaCl}$ had lower growth rates compared with controls (no $\mathrm{NaCl}$ ) by a statistically significant margin $(p<0.01)$, whereas the isolates grown in medium containing $2 \% \mathrm{NaCl}$ did not show statistically significant differences in growth rates compared to the controls. No statistically significant differences were observed after conducting analyses by country of origin (Table 1).

\section{Conidial size}

The arthroconidial sizes for the $C$. posadasii isolates ranged from 2.54 to $3.37 \mu \mathrm{m}$ in width and 4.35 to $8.80 \mu \mathrm{m}$ in length. Isolate HU12 had the largest arthroconidial size, with arthroconidia measuring $2.56 \times 8.80 \mu \mathrm{m}$; however, statistically significant differences in arthroconidial size between HU12 and the other samples tested were not observed $(p<0.05)$.

\section{Genotypic variability and population structure AFLP data analyses}

Six primer combinations yielded 170 amplified AFLP markers. The levels of genetic variation of $C$. posadasii from the MX and AR populations are shown in Table 2. In general, the MX and AR isolates had high genetic variability, as demonstrated by the calculated values for the different genetic diversity estimators (the effective number of alleles, the average heterogeneity and the Shannon Index (I), which is insensitive to the number of isolates analysed). The AMOVA showed that $95.21 \%$ of the molecular variance was distributed within the C. posadasii populations from MX and AR. Our results showed a small genetic differentiation between $C$. posadasii isolates of both countries (Fst $=0.048$, $p=0.0001)$.

Furthermore, the dendrogram for the C. posadasii isolates yielded 10 clusters (Figure 1). The first cluster included two isolates from MX, with 56\% similarity. Group II included 17 isolates from MX and AR with $70 \%$ similarity and showed two subgroups. Subgroup IIa included 9 isolates from AR and one clinical isolate from MX (isolate M1204) with 74\% similarity, and subgroup
Table 1 Growth rates of the C. posadasii isolates in different $\mathrm{NaCl}$ concentrations

\begin{tabular}{|c|c|c|c|c|}
\hline \multicolumn{5}{|c|}{ Growth rates (cm/day) } \\
\hline Isolate & $\mathrm{NaCl}(0 \%)$ & $\mathrm{NaCl}(2 \%)$ & $\mathrm{NaCl}(4 \%)$ & $\mathrm{NaCl}(6 \%)$ \\
\hline M0104 & 3.48 & 3.55 & 2.28 & 1.4 \\
\hline M1204 & 3.45 & 3.11 & 1.63 & 0.75 \\
\hline M1404 & 2.83 & 2.9 & 1.58 & 0.66 \\
\hline M1505 & 2.85 & 2.8 & 1.93 & 1.06 \\
\hline M2305 & 2.18 & 2.15 & 1.6 & 1.03 \\
\hline M2805 & 3.01 & 2.95 & 2.03 & 1.23 \\
\hline M3005 & 2.35 & 2.46 & 1.31 & 0.98 \\
\hline M3905 & 3.68 & 3.4 & 1.8 & 1.06 \\
\hline M5406 & 2.91 & 3.6 & 2.5 & 1.13 \\
\hline M5708 & 2.7 & 3.51 & 2.23 & 1.31 \\
\hline HU1 & 3.58 & 3.78 & 2.58 & 1.3 \\
\hline $\mathrm{HU} 2$ & 3.13 & 3.91 & 2.1 & 1.05 \\
\hline HU11 & 3.63 & 3.28 & 2.23 & 1.43 \\
\hline $\mathrm{HU} 12$ & 3.56 & 3.65 & 2.43 & 1.13 \\
\hline HU18 & 3.21 & 3.15 & 2 & 1.16 \\
\hline HU19 & 2.26 & 2.6 & 1.63 & 0.9 \\
\hline $\mathrm{HU} 24$ & 3.45 & 3.5 & 2.06 & 1.26 \\
\hline 37.3 & 3.5 & 3.8 & 2.45 & 1.48 \\
\hline 5256 & 2.88 & 2.5 & 2 & 2.86 \\
\hline MA & 3.45 & 3.4 & 2.1 & 1.01 \\
\hline SiFe & 3.11 & 3.36 & 2.2 & 1.18 \\
\hline 972579 & 3.05 & 3.35 & 2.11 & 1.26 \\
\hline 073089 & 3.68 & 3.48 & 2.3 & 1.26 \\
\hline 073094 & 3.53 & 3.1 & 2.16 & 1.1 \\
\hline 073129 & 3.58 & 3.6 & 2.13 & 1.11 \\
\hline 073130 & 2.88 & 2.86 & 1.46 & 0.95 \\
\hline 073131 & 3.73 & 3.48 & 2.4 & 1.36 \\
\hline 083376 & 2.65 & 2.91 & 1.61 & 0.9 \\
\hline 083377 & 3.53 & 3.25 & 2.26 & 2.5 \\
\hline 083380 & 3.16 & 3.46 & 1.93 & 1.28 \\
\hline 083382 & 2.43 & 3.08 & 1.78 & 1.11 \\
\hline 083381 & 3.05 & 2.96 & 2.73 & 1.05 \\
\hline
\end{tabular}

IIb included 7 isolates from MX, with $73 \%$ similarity. Group III contained three isolates from MX with $73 \%$ intragroup similarity. Group IV consisted of one isolate from MX with $62 \%$ intragroup similarity. Group V consisted of two isolates from MX with 71\% similarity. Group VI consisted of two isolates, one from MX and another from AR, with 70\% similarity. Group VII included only one isolate (isolate 083381) from AR, with $63 \%$ similarity to group VI. Group VIII included two isolates from MX, with 65\% similarity. Group IX consisted of only one isolate from MX, with $36 \%$ similarity with 
Table 2 Polymorphism, effective number of alleles, genetic diversity and expected heterozygosity of C. posadasii isolates from $M X$ and $A R$

\begin{tabular}{lllll}
\hline Populations & $\mathbf{P}(\%)$ & $\boldsymbol{n}_{\mathrm{e}}$ & $\boldsymbol{l}$ & $\boldsymbol{h}$ \\
\hline C. posadasii (MX) & 91.76 & $1.5970 \pm 0.0603$ & $0.5011 \pm 0.0382$ & $0.3396 \pm 0.0289$ \\
C. posadasii (AR) & 71.76 & $1.4754 \pm 0.0694$ & $0.3951 \pm 0.0503$ & $0.2687 \pm 0.0361$ \\
\hline
\end{tabular}

$\mathrm{P}$ (polymorphism); $n_{e}$ (effective number of alleles); I (genetic diversity, Shannon's index); h (heterozygosity). $\mathrm{MX}$ (Mexico); AR (Argentina).

the above. Finally, group $\mathrm{X}$ included only one isolate from MX, with $35 \%$ similarity. The cophenetic correlation coefficient $(\mathrm{CCC} r=0.948, p=0.0004)$ suggested that the dendrogram accurately represented the original genetic similarities among the isolates.

The network of haplotypes demonstrated a large number of crosslinks among $C$. posadasii isolates and showed a small differentiation between the isolates from MX and AR.

Additionally, the number of mutations between each node (1-30) in the haplotype network demonstrated broad genetic variability (Figure 2 ).

Finally, the $I_{A}(0.0287)$ calculated for the isolates in this study suggested that these isolates have a recombinant reproductive system.

\section{Discussion}

The spread of coccidioidomycosis over recent years in endemic areas of MX and AR is sufficient to warrant attention given that there are so few studies of the disease. Therefore, it is important to be well informed about the different aspects of Coccidioides spp. to carefully manage the disease. In this study, we estimated the genetic variability among $C$. posadasii isolates from $M X$ and $A R$. Our results indicate that the partial Ag2/PRA Coccidioides spp. sequences obtained by Bialek et al. [21] method are useful for identify $C$. posadasii from different geographical origins. This fragment can also be used to identify $C$. immitis because this species presents in this region a deletion of 12 bases [36]. Thus, this fragment is not suitable to diversity or genetic structure studies, because it presents scarce variation. On the other hand, the results of phenotypic characterisation parameters (growth rates using different $\mathrm{NaCl}$ concentrations and arthroconidial size) showed no differences among the $C$. posadasii isolates.

The genetic diversity of the $C$. posadasii isolates from MX and AR showed high genetic variability using polymorphic AFLP. However, AMOVA indicated that this variation was not geographically structured. The results from this study suggested high rates of gene flow between isolates in MX and AR, which explains the scarce

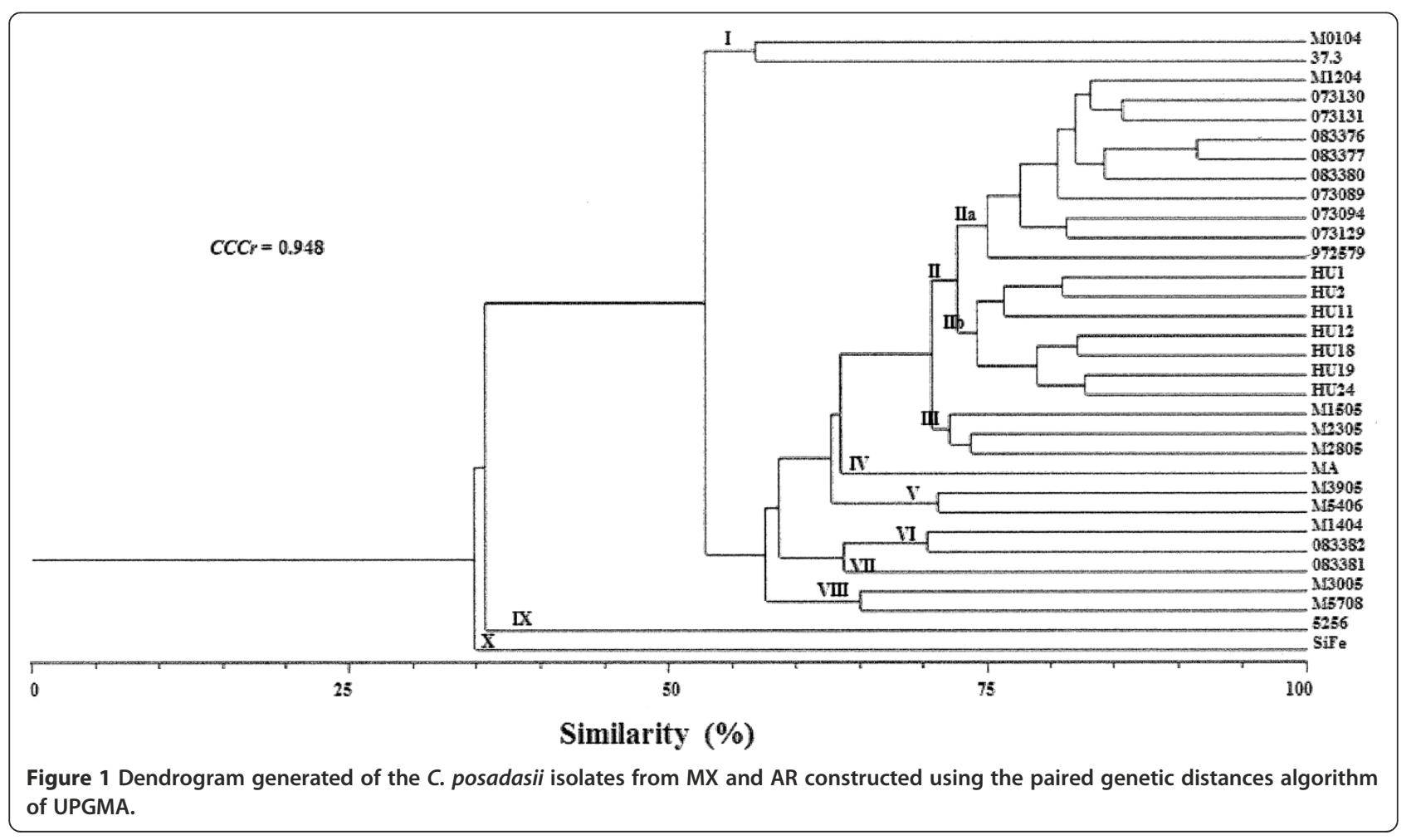




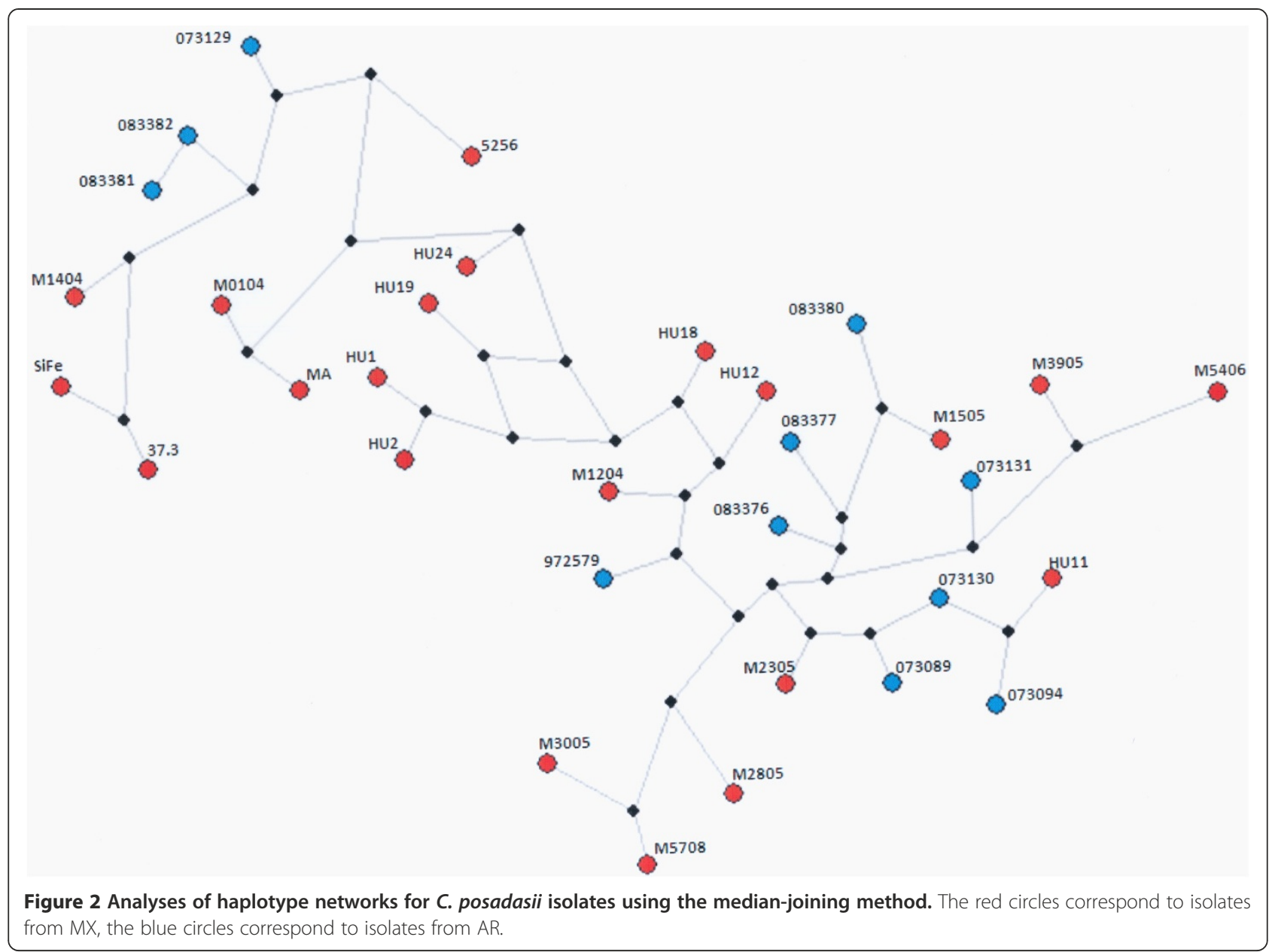

differentiation found among them. A probable explanation about these findings may be the constant flow of genes between these populations favoring the air-borne dissemination of the fungus since the hyphae that constitute the saprobe or infectious stage fragment even with the lightest air currents, freeing the arthroconidia and easily travelling large distances in the wind $[37,38]$. The viability of the conidia in the environment is favored by the tolerability of the fungi to high temperatures $\left(50^{\circ} \mathrm{C}\right)$ and their resistance to UV light (due to their melanine content) benefiting survival and longevity. Another possible explanation maybe high gene flow is a consequence of the constant movement of people across the continent or due to the migration of mammals [39], among these specific bat species which are long-distance migratory. This hypothesis is supported by the recent findings by Cordeiro et al. [40] who demonstrated the infection by Coccidioides spp. in these mammals.

The no-association among the $C$. posadasii isolates from MX and AR with their geographical origin, was supported by the dendrogram and haplotype network, confirm the scarce genetic differentiation observed between them. These findings partially concur with Fisher et al. [39], who found low variability among Coccidioides spp. isolates and little genetic differentiation among isolates from South America and the US. Notwithstanding, the technique used in this study was the AFLP. This is a useful tool for establishing the changes in the genome of the fungi isolates allowing for simultaneously analysing many loci and detecting a greater number of polymorphic DNA markers than any other method based on PCR. However, a limiting factor in this study was the impossibility of comparing results with other studies on the structure of Coccidioides spp. populations due to the use of different methodologies. It is recommended that future studies use markers that have been validated and employed by other authors in studies of genetic variability of Coccidioides spp. in order to compare the results obtained with isolates from different geographic regions.

On the other hand, the high genetic variability found among the isolates studied maybe explained by a recombinant sexual reproductive system $\left(I_{A}=0.0287\right)$, as was suggested by other authors $[1,13-17,41,42]$. This mode of 
reproduction was also supported by the presence of the potentially functional MAT idiomorph loci, MAT1-2 (HMG) and MAT1-1 (alpha-box) [41,42]. Thus, even though this species' sexual phase remains undescribed, studies indicate that, based on high variability, these fungi recombine, gaining advantages such as adaption to new environments; thus, virulent or resistant strains could emerge, which may also explain the numerous recent epidemic outbreaks.

The observed high variability may also be explained by the possibility that the different genotypes could adapt to other environments under inappropriate developmental conditions, which is true for the isolate "MA", found in a patient originally from the state of Campeche, located in the Southeast region of MX, who claimed to have never left the state. This region has climatic conditions different from the preferred fungal growth conditions. Similarly, adaptation to new environments facilitates the appearance of hypervirulent strains, as suggested by Fisher et al. [1] and Jewell et al. [18].

It is important to understand variability among these fungi, which has also been investigated in recent publications, to determine genotype distributions among populations, monitor outbreaks, assess variations in virulence and predict disease progression $[18,43,44]$. Several lines of research that pertain to this issue are in progress that will further our understanding of the underlying biology of these pathogens and their interactions with other living species.

\section{Conclusions}

Phenotypic characterisation indicated no differences among the $C$. posadasii isolates studied. The different estimators of genetic variability employed indicated that the isolates from MX and AR had high genetic variability. The AMOVA showed a small genetic differentiation among the C. posadasii populations analysed from MX and AR; thus, these populations were genetically similar. Furthermore, the $I_{A}$ calculated for the isolates suggested that the C. posadasii isolates had recombinant reproductive systems, which would contribute to the high variability found among the isolates.

\section{Additional files}

\section{Additional file 1: Source and geographic origin of Coccidioides} posadasii isolates.

Additional file 2: Binary data matrix. Each AFLP band was treated as a separate character and scored 1 (present) or 0 (absent).

Additional file 3: The 32 isolates of Coccidioides spp. from MX and AR were identified as $C$. posadasii trough of the phylogenetic inference analysis.

\section{Competing interests}

The authors declare that they have no competing interests.

\section{Authors' contributions}

MRRM, EDE were involved in the study design, analised and interpreted the results and drafted the manuscript. EDE and MGFDL performed the experiments. GZ conducted data analysis and participated in drafting the manuscript and provided a critical review of the manuscript. CC participated in the study design and provided a critical review of the manuscript. RCO performed microscopic fungal identification. MRRM conceptualized and coordinated the project. All authors read and approved the final manuscript.

\section{Acknowledgements}

This paper is a partial fulfilment for the graduate Program in Biological Sciences of the National Autonomous University of Mexico (UNAM). E. Duarte-Escalante acknowledges support from the Program in Biological Sciences.

This project was funded by PAPIIT-DGAPA (IN215509-3).

The authors would like to thank to Actuary Dolores Hernández who provided statistical analysis support.

\section{Author details}

'Departamento de Microbiología y Parasitología, Facultad de Medicina, Universidad Nacional Autónoma de México (UNAM), Ciudad Universitaria No. 3000, México, D. F. 04510, México. ²Departamento de Zoología, Escuela Nacional de Ciencias Biológicas, Instituto Politécnico Nacional, Prol. de Carpio y Plan de Ayala. Col. Sto. Tomás, 11340, México, D. F., México. ${ }^{3}$ División de Investigación, Hospital Juárez de México, Edificio E. Av. Instituto Politécnico Nacional 5160, Col. Magdalena de las Salinas, 07760, México, D. F., México. ${ }^{4}$ Departamento de Micología, INEI ANLIS "Dr. Carlos G. Malbrán", Av. Velez Sarsfield 563, 1281, Buenos Aires, Argentina.

Received: 18 January 2013 Accepted: 30 August 2013

Published: 3 September 2013

\section{References}

1. Fisher MC, Koenig GL, Taylor JW: Molecular and phenotypic description of Coccidioides posadasii sp. Nov., previously recognized as the non-California population of Coccidioides immitis. Mycologia 2002, 94:73-84.

2. Hector RF, Laniado-Laborín R: Coccidioidomycosis A fungal disease of the Americas. PloS Med 2005, 2:e2.

3. Fisher FS, Bultman MW, Johnson SM, Pappagianis D, Zaborsky E: Coccidioides niches and habitat parameters in the Southwestern United States. A matter of scale. Ann NY Acad Sci 2007, 1111:47-72.

4. Kolivras KN, Johnson PS, Comrie AC, Yool AR: Environmental variability and coccidioidomycosis (valley fever). Aerobiologia 2001, 17:31-42.

5. Kolivras KN, Comrie AC: Modeling valley fever (coccidioidomycosis) incidence on the basis of climate conditions. Int J Biometeorol 2003, 47:87-101.

6. Laniado-Laborín R, Alcantar-Schramm JM, Cazares-Adame R: Coccidioidomycosis: an update. Curr Fungal Infect Rep 2012, 6:113-120.

7. Laniado-Laborín R: Expanding understanding of epidemiology of coccidioidomycosis in the western hemisphere. Ann NY Acad Sci 2007, 1111:19-34

8. Canteros CE, Madariaga MJ, Lee W, Rivas MC, Davel G, lachini R: Agentes de micosis endémicas en un área rural de Argentina: estudio seroepidemiológico en perros. Rev Iberoam Micol 2010, 27:14-19.

9. Hector RF, Rutherford GW, Tsang CA, Erhart LM, McCotter O, Anderson SM, Komatsu K, Tabnak F, Vugia DJ, Yang Y, Galgiani JN: The public health impact of coccidioidomycosis in Arizona and California. Int J Environ Res Public Health 2011, 8:1150-1173.

10. Laniado-Laborín R: Coccidioidomycosis and other endemic mycoses in Mexico. Rev Iberoam Micol 2007, 24:249-258.

11. Baptista Rosas RC, Riquelme M: Epidemiología de la coccidioidomicosis en México. Rev Iberoam Micol 2007, 24:100-105.

12. Canteros CE, Toranzo A, Ibarra-Camou B, David V, Carrizo SG, Santillán-Iturres A, Serrano J, Fernández N, Capece P, Gorostiaga J, Chacón YA, Tonelli R, Boscaro G, Abiega C, Mendieta S, Fernández C, Fernández A, Vitale R, Santos P, Pizarro MR, López-Joffre MC, Lee W, Mazza M, Posse G, Tiraboschi IN, Negroni R, Davel G: La coccidioidomicosis en Argentina, 1892-2009. Rev Arg Microbiol 2010, 42:261-268. 
13. Burt A, Carter DA, Koenig GL, Whites TJ, Taylor JW: Molecular markers reveal cryptic sex in the human pathogen Coccidioides immitis. Proc Natl Acad Sci USA 1996, 93:770-773.

14. Burt A, Dechairo BM, Koening GL, Carter DA, White TJ, Taylor JW: Molecular markers reveal differentiation among isolates of Coccidioides immitis from California, Arizona and Texas. Mol Ecol 1997, 6:781-786.

15. Koufopanou V, Burt A, Taylor JW: Concordance of gene genealogies reveals reproductive isolation in the pathogenic fungus Coccidioides immitis. Proc Natl Acad Sci USA 1997, 94:5478-5482.

16. Koufopanou V, Burt A, Taylor JW: Concordance of gene genealogies reveals reproductive isolation in the pathogenic fungus Coccidioides immitis [correction]. Proc Nat Acad Sci USA 1998, 95:8414.

17. Fisher MC, Koening GL, White TJ, Taylor JW: Pathogenic clones versus environmentally driven population increase: analysis of an epidemic of the human fungal pathogen Coccidioides immitis. J Clin Microbiol 2000, 38:807-813

18. Jewell K, Cheshier R, Cage GD: Genetic diversity among clinical Coccidioides spp. isolates in Arizona. Med Mycol 2008, 46:449-455.

19. Williams RH, Ward E, McCartney HA: Methods for integrated air sampling and DNA analysis for the detection of airborne fungal spores. Appl Environ Microbiol 2001, 67:2453-2459.

20. Calderón C, Ward E, Freeman J, McCartney A: Detection of airborne fungal spores sampled by rotating-arm and Hirst-type spore traps using polymerase chain reaction assays. J Aerosol Sci 2002, 3:283-296.

21. Bialek R, Kern J, Herrmann T, Tijerina R, Cecenas L, Reischl U, Gonzalez GM: PCR assays for identification of Coccidioides posadasii based on the nucleotide sequence of the antigen 2/proline-rich antigen. J Clin Microbiol 2004, 42:778-783.

22. Altschul S, Madden T, Shäffer A, Zhang J, Zhang Z, Miller W, Lipman A: Gapped BLAST and PSI-BLAST: a new generation of protein database search programs. Nucleic Acids Res 1997, 25:3389-3402.

23. Vos $P$, Hogers $R$, Bleeker $M$, Reijans $M$, Van de Lee $T$, Hornes M, Frijters $A$, Pot J, Peleman J, Kuiper M, Zabeau M: AFLP: a new technique for DNA fingerprinting. Nucleic Acids Res 1995, 23:4407-4414.

24. Duarte-Escalante E, Zúñiga G, Nava-Ramírez O, Córdoba S, Refojo N, Arenas $R$, Delhaes $L$, Reyes-Montes MR: Population structure and diversity in the pathogenic fungus Aspergillus fumigatus isolates from different sources and geographic origins. Mem I Oswaldo Cruz 2009, 104:427-433.

25. Allnut TR, Newton AC, Lara A, Premoli A, Armesto JJ, Vergara R, Gardner M: Genetic variation in Fitzroya cupressoides (alerce), a threatened South American conifer. Mol Ecol 1999, 8:975-987.

26. Nei M: Analysis of gene diversity in subdivided populations. Proc Nat Acad Sci USA 1973, 70:3321-3323.

27. Zhivotovsky LA: Estimating population structure in diploids with multilocus dominant DNA markers. Mol Ecol 1999, 8:907-913.

28. Schlüter PM, Harris SA: Analysis of multilocus fingerprinting data sets containing missing data. Mol Ecol Notes 2006, 6:569-572

29. Excoffier L, Smouse PE, Quattro JM: Analysis of molecular variant inferred from metric distances among DNA haplotypes: application to human mitochondrial DNA restriction data. Genetics 1992, 131:479-491.

30. Manly BFJ: Randomization, Bootstrap, and Montecarlo Methods in Biology. London: Chapman and Hall; 1997.

31. Rohlf FJ: Numerical taxonomy and multivariate analysis system. New York: Exeter Software Inc; 1998.

32. Bandelt HJ, Forster $P$, Röhl A: Median-Joining networks for inferring intraspecific phylogenies. Mol Biol Evol 1999, 16:37-48.

33. Polzin T, Daneschmand SV: On Steiner trees and minimum spanning trees in hypergraphs. Oper Res Lett 2003, 31:12-20.

34. Maynard-Smith J, Smith NH, O'Rourke M, Spratt BG: How clonal are bacteria? Proc Natl Acad Sci U S A 1993, 90:4384-4388.

35. Haubold B, Hudson RR: LIAN 3.0: detecting linkage disequilibrium in multilocus data. Bioinformatics 2000, 16:847-848.

36. Canteros CE, Toranzo A, Suárez-Alvarez R, Davel G, Castañón-Olivares LR, Napoli J: Identidad genética del hongo causante del primer caso de coccidioidomicosis descripto por Alejandro Posadas en 1892. Medicina (Buenos Aires) 2009, 69:215-220.

37. Pappagianis D, Einstein H: Tempest from Tehachapi takes toll or Coccidioides conveyed aloft and afar (Medical Information). West J Med 1978, 129:527-530.

38. Laniado-Laborín R: Coccidioidomicosis. Más que una enfermedad regional. Rev Inst Nal Enf Resp Mex 2006, 19:301-308.
39. Fisher MC, Koenig GL, White TJ, San-Blas G, Negroni R, Gutiérrez-Álvarez I, Wanke B, Taylor JW: Biogeographic range expansion into South America by Coccidioides immitis mirrors New World patterns of human migration. Proc Natl Acad Sci USA 2001, 98:4558-4562.

40. Cordeiro RA, Silva KRC, Brilhante RSN, Moura FBP FBP, Duarte NFH, Marques FJF FJF, Cordeiro RA, Moreira Filho RE, Araújo RWB, Bandeira TJPG, Rocha MFG, Sidrim JJC: Coccidioides posadasii Infection in bats, Brazil. Emerg Infect Diseases 2012, 18:668-670.

41. Fraser JA, Stajich JE, Tarcha EJ, Cole GT, Inglis DO, Sil A, Heitman J: Evolution of the mating type locus: insights gained from the dimorphic primary fungal pathogens Histoplasma capsulatum, Coccidioides immitis, and Coccidioides posadasii. Eukaryot Cell 2007, 6:622-629.

42. Mandel MA, Barker BM, Kroken S, Rounsley SD, Orbach MJ: Genomic and population analyses of the mating type loci in Coccidioides species reveal evidence for sexual reproduction and gene acquisition. Eukaryot Cell 2007, 6:1189-1199.

43. Neafsey DE, Barker BM, Sharpton TJ, Stajich JE, Park DJ, Whiston E, Hung C, McMahan C, White J, Sykes S, Heiman D, Young S, Zeng Q, Abouelleil A, Aftuck L, Bessette D, Brown A, FitzGerald M, Lui A, Macdonald JP, Priest M, Orbach MJ, Galgiani JN, Kirkland TN, Cole GT, Birren BW, Henn MR, Taylor JW, Rounsley SD: Population genomic sequencing of Coccidioides fungi reveals recent hybridization and transposon control. Genome Res 2010, 20:938-946.

44. Sharpton TJ, Stajich JE, Rounsley SD, Gardner MJ, Wortman JR, Jordar VS, Maiti R, Kodira CD, Neafsey DE, Zeng Q, Hung C, McMahan C, Muszewska A, Grynberg M, Mandel MA, Kellner EM, Barker BM, Galgiani JN, Marc J, Orbach MJ, Kirkland TN, Cole GT, Henn MR, Birren BW, Taylor JW: Comparative genomic analyses of the human fungal pathogens Coccidioides and their relatives. Genome Res 2009, 19:1722-1731.

doi:10.1186/1471-2334-13-411

Cite this article as: Duarte-Escalante et al:: AFLP analysis reveals high genetic diversity but low population structure in Coccidioides posadasii isolates from Mexico and Argentina. BMC Infectious Diseases 2013 13:411.

\section{Submit your next manuscript to BioMed Central and take full advantage of:}

- Convenient online submission

- Thorough peer review

- No space constraints or color figure charges

- Immediate publication on acceptance

- Inclusion in PubMed, CAS, Scopus and Google Scholar

- Research which is freely available for redistribution
C) Biomed Central 